\title{
El sentido común crítico y la evaluación de las grandes tendencias históricas
}

\section{The critical common sense and the appraisal of the large historical tendencies}

\author{
H. C. F. MANSILLA \\ Academia de Ciencias de Bolivia
}

Recibido: 23-02-2009

Aprobado definitivamente: 03-04-2009

\section{RESUMEN}

Basado en elementos de la filosofía clásica, el common sense británico y la Escuela de Frankfurt, el autor postula un sentido común guiado críticamente, que serviría para evaluar las tendencias históricas y los modelos de modernización en el Tercer Mundo. Evitando extremos, este teorema rechazaría tanto las pretensiones de verdad de muchos enfoques racionalistas como el relativismo epistemológico y ético. La existencia de leyes y etapas obligatorias de la historia es uno de esos extremos; otro es la opción teórica que afirma que los modelos culturales son incomparables e inconmensurables entre sí. La existencia de un solo paradigma normativo-positivo de desarrollo es insostenible, pero igualmente la posición que decreta la diversidad e incomparabilidad totales de los regímenes civilizatorios. Es conveniente adoptar una línea intermedia entre universalismo y particularismo y alcanzar una síntesis fructífera de ambos.

PALABRAS CLAVE

ESCUELA DE FRANKFURT, HABERMAS, KANT, PARTICULARISMO, SENTIDO COMÚN, UNIVERSALISMO

\begin{abstract}
Based on elements of classical philosophy, the British common sense and the Frankfurt School, the author proposes a critically guided common sense, which could be used to evaluate historical tendencies and specially the modernization efforts in the Third World. Avoiding extremes, this theorem rejects the pretensions of truth of rationalist theories and also the epistemic and ethic relativism. The existence of obligatory laws and periods of historical development is one of these extremes; the other one is the position which states that cultural models are incomparable and
\end{abstract}


immeasurable. It is reasonable, for instance, to take a middle way between universalism and particularism and also to reach a fruitful synthesis between both currents.

KEYWORDS

COMMON SENSE, FRANKFURT SCHOOL, HABERMAS, KANT, PARTICULARISM, UNIVERSALISM

LA PREGUNTA DE SI EL DESENVOLVIMIENTO HISTÓRICO tiene un sentido no puede ser respondida directa y fácilmente. Un caso similar es la cuestión en torno al éxito o fracaso de los procesos de modernización en el Tercer Mundo, sobre todo en aquellos países que no han logrado integrarse adecuadamente al mercado mundial. Estos problemas -como el precio ecológico que hay que pagar por el progreso material- pertenecen al género de las grandes cuestiones recurrentes a lo largo de la evolución humana, como la plausibilidad del vínculo entre fe y razón o el sentido último de nuestra existencia, cuestiones que admiten variadas interpretaciones, todas ellas insatisfactorias, y que se hallan en la cercanía del campo metafísico y hasta teológico. El intento de dilucidarlas coherente y exhaustivamente resulta imposible durante la vida de un solo autor, pero esto no nos exime de la necesidad de un esfuerzo sostenido en esta dirección. Además, siguiendo a mis maestros de la Escuela de Frankfurt, trato de evitar definiciones categóricas, esperando que el despliegue argumentativo brinde una idea más o menos aceptable del propósito de estos comentarios.

La abstención de dictámenes valorativos, que se deriva, por ejemplo, del énfasis postmodernista en la incomparabilidad de los sistemas civilizatorios en un contexto multicultural, no sería pertinente en este contexto. Las ciencias sociales tienen que esbozar una respuesta, por más provisoria que sea, a los anhelos de extensos grupos de la población y de innumerables individuos aislados que desean saber si tal o cual experimento sociopolítico ha sido realmente provechoso en la perspectiva de largo plazo y si vale la pena imitarlo en otros países y otras regiones. En una palabra: mucha gente tiene el legítimo interés de conocer los criterios que se hallan en la base o detrás de los trabajos de los especialistas para luego decidirse por un modelo sociopolítico o por otro. Para cumplir este objetivo necesariamente hay que emitir un juicio valorativo, y para ello el sentido común guiado críticamente puede resultar un instrumento adecuado. Este concepto alude de manera manifiesta a la Escuela de Frankfurt, y dentro de ella a autores tan dispares como Theodor W. Adorno, Erich Fromm y Jürgen Habermas. Es un ensayo de combinar esta notable corriente teórica con elementos provenientes del vasto acervo anglosajón, que en este campo se extiende desde Sir Francis Bacon (un genuino representante de un common sense enriquecido por una dilatada experiencia política) y la Escuela Escocesa ${ }^{1}$ hasta el pragmatismo norteamericano de Charles S. Peirce.

1 Dentro del marco de la Ilustración Escocesa surgió la corriente inspirada por Thomas Reid (1710-1796), llamada también la escuela escocesa del sentido común, que ha tenido importantes 
Un ejemplo de sentido común crítico es la distancia que se debió mantener frente a la enorme producción de teorías y diagnósticos sobre el desarrollo ineludible - el socialista- que parecía obligatorio para el llamado Tercer Mundo. Hasta 1989 / 1991 la inmensa, pero vana divulgación de doctrinas falaces e inútiles, provenientes de las diversas tendencias marxistas, opacaba y convertía en casi clandestinas las opiniones adversas a los regímenes revolucionarios y a los «movimientos de liberación nacional». Los más activos propagandistas de tales concepciones sostienen ahora la cómoda ocurrencia de que ha llegado el fin del Tercer Mundo (como concepto que tuviera sentido) y que ha fracasado, por consiguiente, la «gran teoría» sobre su evolución. Lo sintomático de esta posición es que estos autores olvidan premeditadamente lo que propugnaban entonces con marcado entusiasmo y hasta fanatismo, y en la actualidad se consagran a lo que hacían sus adversarios: a reconocer los aspectos positivos del desarrollo capitalista, incluyendo su aporte a la moderna democracia pluralista. ${ }^{2}$

Una aproximación más adecuada a esta importante temática es, por ejemplo, la intentada por Hans Küng, quien mediante su extensa obra ha tratado de utilizar de manera fructífera los aspectos religiosos y las reflexiones teológicas para aclarar problemas sociales y políticos. El sentido común crítico que se puede derivar de algunos fragmentos de la tradición religioso-teológica nos puede brindar algunos elementos de juicio para evaluar las tendencias sociales. Küng aseveró que el impulso primordial de las grandes religiones proféticas reside en una relación dialógica entre Dios y el hombre, en una ética de humanidad elemental y en un sentido histórico del desarrollo del mundo y de los seres humanos. ${ }^{3}$ Si existe algo así como un código moral común a todos los mortales, una convicción de carácter ecuménico en torno a la unidad del género humano y un desarrollo histórico que no es totalmente arbitrario y fortuito, podemos entonces aseverar que nuestro mundo posee algo que le brinda un sentido más o menos permanente, aunque sea muy arduo expresar este sentido en un idioma racional y aceptado en el ámbito moderno.

Este principio englobante se vislumbra, por ejemplo, cuando se reconoce que el Estado de Derecho contemporáneo, liberal-democrático y secular, está basado

derivaciones en el campo político. Cf. Josep Baqués Quesada, «La Ilustración escocesa: ¿un depósito de intuiciones para el neoconservadurismo?», en Revista de Estudios Politicos (Madrid), $\mathrm{n}^{\circ} 118$, octubre-diciembre de 2002, pp. 143-180.

$2 C f$. la exculpación y auto-estilización de esta escuela (inspirada por Dieter Senghaas) y su adaptación a las corrientes de moda: Ulrich Menzel, Das Ende der Dritten Welt und das Scheitern der grossen Theorie (El fin del Tercer Mundo y el fracaso de la gran teoría), Frankfurt: Suhrkamp, 1992 , pp. 68, 125 sq.

3 Hans Küng, Der Islam. Geschichte, Gegenwart, Zukunft (El Islam. Historia, presente, futuro), Munich: Piper 2006, p. 130.- El hombre sería el amigo de Dios según las religiones derivadas del tronco de Abraham: ibid., p. 87. 
en presupuestos normativos prepolíticos que el propio orden político, laico y democrático, no ha creado y no los puede garantizar, como lo afirmó Jürgen Habermas al discutir el rol de la religión y sus complejos nexos con los procesos de secularización. ${ }^{4}$ Estos cimientos normativos prepolíticos tienen que ir hoy acompañados de una atmósfera general de tolerancia pluralista, que sólo la secularización en Europa Occidental y en el Asia Oriental ha sabido brindar con éxito duradero. Estos cimientos impiden el regreso a creencias religiosas exclusivistas y permiten el libre juego de las disonancias cognitivas. ${ }^{5}$ No hay duda, por otra parte, de que la modernidad ha conllevado un progreso en el campo ético, el universalismo de la «moral postconvencional» (Habermas), generalizando un sistema normativo que se legitima mediante los argumentos racionales y no acudiendo a una tradición que estaría por encima del cuestionamiento discursivo.

La evaluación de lo alcanzado hasta ahora y, por consiguiente, de las grandes tendencias de la evolución humana, no puede renunciar a determinadas preguntas, aunque estas sean calificadas de metafísicas o teológicas. Para precisar esta temática no es superfluo retornar a un clásico. Immanuel Kant comenzó su obra más conocida señalando que la razón es asediada por cuestiones que ella no puede rechazar, pues provienen de la naturaleza misma de la razón. ${ }^{6}$ Estas cuestiones, como la existencia de Dios, el inicio del universo, la esencia de la libertad, el sentido del mundo y otras afines, son indemostrables por y para la razón pura, pero, según Kant, ${ }^{7}$ son los postulados fundamentales de la razón práctica. La misma facultad que impide el análisis y la aclaración de las cuestiones metafísicas mediante la razón pura obliga a ponerlas sobre el tapete de una discusión más amplia; este hecho nos muestra las limitaciones propias de la razón. ${ }^{8}$ El porqué

4 En un texto de factura trabajosa y retorcida, Jürgen Habermas llegó a admitir lo positivo y hasta constructivo de factores religiosos para la vida social-política. Habermas, Vorpolitische Grundlagen des demokratischen Rechtsstaates? (Fundamentos prepolíticos del Estado democrático de derecho?), en: Jürgen Habermas / Joseph Ratzinger, Dialektik der Säkularisierung. Über Vernunft und Religion (Dialéctica de la secularización. Sobre razón y religión), Freiburg etc.: Herder, 2006,pp. 15-37, especialmente p. 31 sq. Cf. también el engorroso texto de Hent de Vries, Minimal Theologies. Critiques of Secular Reason in Adorno and Levinas, Baltimore / Londres: Johns Hopkins U. P., 2005.

$5 \quad$ Giovanna Borradori, Die Rekonstruktion des Terrorismusbegriffs nach Habermas (La reconstrucción del concepto de terrorismo según Habermas), en: Jürgen Habermas / Jacques Derrida, Philosophie in Zeiten des Terrors (Filosofía en tiempos del terror), compilación de G. Borradori, Hamburgo: EVA, 2006, pp. 70-113, especialmente p. 103.

6 Immanuel Kant, Kritik der reinen Vernunft (Crítica de la razón pura) [prólogo de 1781, no incluido en la edición posterior de 1787], en: Kant, Werke in zehn Bänden (Obras en diez tomos), compilación de Wilhelm Weischedel, Darmstadt: WBG, 1968, t. 3, p. 11.

7 Immanuel Kant, Kritik der reinen Vernunft, [prólogo a la segunda edición de 1787], en: Kant, Werke..., ibid., t. 3, p. 33 sq.

8 Immanuel Kant, Kritik der praktischen Vernunft (Crítica de la razón práctica) [1788], en: 
de todo lo existente o la contingencia absoluta de toda la creación no es sólo una de las grandes interrogantes teológico-metafísicas, ${ }^{9}$ sino una cuestión básica para juzgar los esfuerzos humanos en la esfera terrenal, por más abstracto y alejado del common sense que parezca este postulado.

Según Sir Isaiah Berlin, cada nueva generación se hace las mismas preguntas, que no pueden ser contestadas mediante un concepto restringido de razón instrumentalista. Estas cuestiones giran en torno al sentido de la vida, la configuración de una existencia bien lograda, el contenido de conceptos como libertad, autoridad y obligación, la voluntad histórica de una comunidad, los vínculos entre individuo e institución y la compleja relación entre poder, eficiencia y orden. ${ }^{10}$ Una visión sólo analítico-descriptiva, por más exacta y aguda que sea, no llega a formular una aproximación fructífera a estas preguntas, como tampoco el impulso universalista del racionalismo y la Ilustración llega a comprender el valor intrínseco de las culturas particulares, una de cuyas funciones más relevantes es brindar una identidad propia e inconfundible a sus miembros.

La abstención de juicios de valor ha estado vinculada a las diversas teorías positivistas y empiricistas, cuya significación en los últimos tiempos no ha dejado de crecer. Uno de los logros perdurables de la Escuela de Frankfurt es (1) haber mostrado exhaustivamente las consecuencias del positivismo aplicado a la praxis sociopolítica y (2) haber diferenciado entre una razón global de los fines y una racionalidad instrumental de los medios. Max Horkheimer abogó por una posición que evitaba dos extremos: la fundición del sujeto y el objeto en una sola entidad o hasta identidad, por un lado, y la estricta separación de ambos en una oposición dualista permanente, por otro. Esta segunda posición, claramente visible en el legado cartesiano, obliga a la razón consagrada a la crítica de los fines a permanecer en una dimensión subjetivista y una actitud contemplativa, que muchas veces deriva en una aceptación acrítica del entorno y casi siempre en una posición apolítica. ${ }^{11}$ En el plano de la prosaica praxis cotidiana, esta gran corriente teórica, prosiguiendo con la abstención de juicios de valor, considera que los esfuerzos científicos

Kant, Werke..., ibid., t. 6, pp. 252-266

9 Karl Löwith, Wissen, Glaube und Skepsis (Saber, creer y escepticismo), Göttingen: Vandenhoeck \& Ruprecht, 1962, p. 80 sq.

10 Isaiah Berlin, Das krumme Holz der Humanität. Kapitel der Ideengeschichte (La madera torcida de la humanidad. Capítulos de la historia de las ideas), Frankfurt: Fischer, 1992, p. 229.

11 Max Horkheimer, Zum Problem der Wahrheit (Sobre el problema de la verdad) [1935], en: Horkheimer, Kritische Theorie. Eine Dokumentation (Teoría crítica. Una documentación), compilación de Alfred Schmidt, Frankfurt: Fischer, 1968,t. I, pp. 228-276, especialmente p. 229, 241 sq.; Max Horkheimer, Zum Rationalismusstreit in der gegenwärtigen Philospophie (Sobre el debate en torno al racionalismo en la filosofía del presente) [1934], en: ibid., t. I,pp. 118-174, especialmente pp. 118-122; Max Horkheimer, Der neueste Angriff auf die Metaphysik (El más reciente ataque a la metafísica) [1937], en: ibid., t. II, pp. 82-136, especialmente pp. 83-85, 115. 
no pueden contribuir a elaborar respuestas y alternativas racionales a cuestiones políticas. El Hombre contemporáneo habitaría necesariamente en la intemperie existencial y en el vacío de valores fundamentados metafísicamente. La política moderna, de índole aporética, se movería entre los extremos conformados por la contingencia y la decisión; las cuestiones políticas tendrían que ser decididas en última instancia, como en el campo de los sentimientos. ${ }^{12}$

Pero aparte de este aspecto es útil señalar que la crítica frankfurtiana a la reducción instrumentalista de la razón no quería caer en argumentaciones metafísicas, en el postulado de que existe algo por afuera y por encima de la evolución social concreta que permitiría actuar como tribunal de la razón para juzgar la historia. Como afirmó Martin Jay, la teoría de Horkheimer negó simultáneamente (a) las pretensiones de verdad absoluta y (b) el relativismo epistemológico y ético. ${ }^{13} \mathrm{El}$ evitar estos extremos es un arduo ejercicio de sentido común guiado críticamente. No es superfluo, sin embargo, mencionar que tampoco la Escuela de Frankfurt logró plasmar explicaciones claras y definiciones operativas de la razón substantiva, contrapuesta a la racionalidad instrumental, y de la verdad histórica. Su fuerte es, como se sabe, una actitud eminentemente crítica (y no tanto un negativismo doctrinario): el análisis inexorable de la sociedad moderna, enraizado en los hechos y las teorías de la misma, pero manteniendo una distancia adecuada frente a ella. Uno de sus instrumentos más útiles es la crítica inmanente: confrontar la realidad socio-política de un momento con sus pretensiones programáticas y los elementos definitorios de su identidad.

Adicionalmente: elementos del sentido común crítico pueden ser ganados de la crítica del racionalismo dogmático. La Escuela de Frankfurt ha volcado su atención a las grandes paradojas de la actualidad: guerras civiles, odios raciales, una pobreza inimaginable, la destrucción de la naturaleza y la prevalencia de nuevas «verdades políticas» en medio del desarrollo más notable de la racionalidad instrumental de toda la historia universal. Una «vida averiada» (Theodor W. Adorno) al lado de la prosperidad más notable. Nuestros mejores sistemas políticos y nuestros esfuerzos teóricos más reputados no alcanzan para comprender y menos para mitigar esta

12 Karl R. Popper y Hannah Arendt no fueron extraños a esta teoría, que nos brinda el consuelo de que el propio actuar debe superar las aporías de la acción. $C f$. Thorsten Bonacker, Die Kontingenz politischen Handelns. Adorno, Arendt und die Legitimationsprobleme in der politischen Gesellschaft (La contingencia de la acción política. Adorno, Arendt y los problemas de legitimación en la sociedad política), en: Dirk Auer et al. (comps.), Arendt und Adorno (Arendt y Adorno), Frankfurt: Suhrkamp, 2003, pp. 286-310.

$13 C f$.el brillante estudio de Martin Jay, The Dialectic Imagination. A History of the Frankfurt School and the Institute of Social Research, 1923-1950, Boston / Toronto: Little Brown, 1973, pp. 61-63. Jay dice refiriéndose a la teoría crítica de Horkheimer: «Dialectics was superb at attacking other systems' pretensions to truth, but when it came to articulate the ground of its own assumptions and values, it fared less well» (ibid., p. 63). 
constelación en la praxis. ${ }^{14}$ Es de justicia señalar una curiosa paradoja del pensamiento contemporáneo. La Escuela de Frankfurt, que tematizó la dialéctica entre razón substancial (de los fines) y racionalidad instrumental (de los medios), llegó a postular el predominio universal e irrestricto de esta última en todas las esferas de la vida social, como si fuese la característica inescapable de la era moderna, renunciando así a su propia distinción entre las dos naturalezas de la razón. Los pensadores frankfurtianos han llegado a subsumir tout court el potencial crítico de la reflexión bajo las manifestaciones del instinto de autopreservación. ${ }^{15}$ Mediante esta operación la Escuela de Frankfurt, que no pudo o no quiso resistir la seducción del pensamiento de Friedrich Nietzsche, se ha privado del mejor instrumento para un análisis diferenciado de la realidad social contemporánea. ${ }^{16}$

Por todo ello se puede aseverar lo siguiente. Al ejercer un juicio valorativo matizado sobre las etapas del desarrollo histórico no podemos dejar de lado los elementos rescatables del orden premoderno. $\mathrm{O}$ dicho en tono enfático: la marcha triunfal de la razón instrumentalista ha generado algunos traumas recurrentes, y la consciencia intelectual no puede eximirse de analizarlos. El recuerdo de otras épocas y otras posibilidades de organización social nos otorga la necesaria distancia crítica para apreciar el presente y evitar una apología de lo alcanzado por el Hombre en los últimos doscientos años, que es mayoritariamente el éxito de la ciencia y la tecnología. El recuerdo del mundo premoderno nos ofrece algunos criterios razonables de apreciación, si observamos, por ejemplo, la destrucción del medio ambiente, la decadencia estética y la declinación ética ${ }^{17}$ que caracterizan parcialmente la modernidad. La soledad existencial del Hombre moderno, los fenómenos de alienación y cosificación ${ }^{18}$ en la vida laboral y social y los aspectos

14 Gilda Waldman, Max Horkheimer: un diálogo inconcluso, en: Gina Zabludovsky (comp.), Teoría sociológica y modernidad. Balance del pensamiento clásico, México: UNAM / Plaza \& Valdés, 1998, p. 247 sq.

15 Jürgen Habermas, Der philosophische Diskurs der Moderne. Zwölf Vorlesungen (El discurso filosófico de la modernidad. Doce lecciones), Frankfurt: Suhrkamp, 1985, p. 108, 119 sq., $137,156$.

16 Jürgen Habermas, Max Horkheimer: zur Entwicklungsgeschichte seines Werkes (Max Horkheimer: sobre la historia de la evolución de su obra), en: Habermas, Texte und Kontexte (Textos y contextos), Frankfurt: Suhrkamp 1991,p. 97 sq., 101. Sobre las relaciones entre Nietzsche, Adorno y Horkheimer cf. Norbert Rath,Zur Nietzsche-Rezeption Horkheimers und Adornos (Sobre la recepción de Nietzsche por Horkheimer y Adorno), en: Willem van Reijen / Gunzelin Schmid Noerr (comps.), Vierzig Jahre Flaschenpost: «Dialektik der Aufklärung» 1947-1987 (Cuarenta años de mensaje en botella: la «Dialéctica de la Ilustración» 1947-1987), Frankfurt: Fischer, 1987, pp. 73-110.

17 Hasta las obras más refinadas de la ética postmodernista no nos ofrecen criterios sólidos para la actuación social y política en la vida cotidiana. Cf. por ejemplo: Zygmunt Bauman, Postmoderne Ethik (Etica postmoderna), Hamburgo: Hamburger Institut für Sozialforschung, 1995 , passim.

18 Axel Honneth, Verdinglichung. Eine anerkennungstheoretische Studie (Cosificación. Un 
monstruosos vinculados al desarrollo de la ciencia y la tecnología nos obligan a ver con otros ojos -más favorables- el mundo premoderno.

No hay duda de que vivimos en una «sociedad de riesgo», ${ }^{19}$ que produce un número muy elevado de amenazas y situaciones de peligro -por ejemplo en el campo ecológico y de los recursos naturales-, que no pueden ser controladas o mantenidas a raya por factores tales como el sentimiento de responsabilidad, autolimitación y repartición de daños y riesgos. Estos últimos se distinguen porque no tienen ninguna solución clara, lo que menoscaba el gran proyecto de la modernidad: la factibilidad de los designios humanos. La sociedad industrial del presente, que promete bienestar a todos, genera inexorablemente una destrucción equivalente. ${ }^{20}$ Para ello la única solución viable es volver al principio clásico de la moderación: algo que es fácil de enunciar y difícil que llevar a cabo. Más difícil aun si seguimos a Manfred Wöhlcke, para quien la sociedad contemporánea denota una propensión irrefrenable a la entropía social, a la desestructuración de sus principios organizativos y a la crisis ecológica y demográfica, a lo cual contribuiría asimismo la democratización generalizada ${ }^{21}$-argumento difícil de ser digerido en el Tercer Mundo.

A esta visión más sobria de la actualidad y, simultáneamente, más respetuosa de la realidad empírica, parece contribuir el llamado «giro histórico» en las ciencias sociales y políticas, que desplaza el «giro lingüístico», la importancia de la epistemología y el relativismo axiológico que prevalecieron en las últimas décadas del siglo XX. ${ }^{22}$ Con un gran éxito de divulgación, Jan Assmann ha fundamentado este giro histórico desde una perspectiva inesperada: la egiptología y los estudios clásicos enriquecidos por el psicoanálisis freudiano. ${ }^{23}$

estudio en la teoría del reconocimiento), Frankfurt: Suhrkamp, 2005, estudio basado en el dictum de Horkheimer y Adorno: «Toda cosificación es un olvido».

19 Ulrich Beck, Risikogesellschaft. Auf dem Weg in eine andere Moderne (La sociedad de riesgo. En camino a una otra modernidad), Frankfurt: Suhrkamp, 1986, passim; Ulrich Beck, Was ist Globalisierung? (Qué es globalización), Frankfurt: Suhrkamp, 1999, p. 73 sqq.

20 Ulrich Beck, Die Erfindung des Politischen.Zu einer Theorie reflexiver Modernisierung (La invención de lo político. Sobre una teoría de la modernización reflexiva), Frankfurt: Suhrkamp, 1993, p. 37 sq., 47, 58 sq., 67.

21 Manfred Wöhlcke, Soziale Entropie.Die Zivilisation und der Weg allen Fleisches (Entropía social. La civilización y el camino de toda carne), Munich: dtv, 1996, p. 15, 27, 171.

22 T. McDonald, The Historic Turn in the Human Sciences, Michigan: University of Michigan Press 1996; María de los Angeles Fernández Ramil, «La ciencia política en el diván: la introspección disciplinar», en Revista de Investigaciones Politicas y Sociologicas (Santiago de Compostela), vol. 4 (2005), n 2, pp. 11-30; M. Jerez Mir, Ciencia política, un balance de fin de siglo, Madrid: Centro de Estudios Políticos y Constitucionales, 1999.

23 Jan Assmann, Moses der Ägypter. Entzifferung einer Gedächtnisspur (Moisés el Egipcio. Desciframiento de una huella de la memoria), Frankfurt: Fischer, 2007, p. 236. Cf. también: Donald P. Spence, Narrative Truth and Historical Truth. Meaning and Interpretation in Psychoanalysis, 
Adicionalmente el sentido común guiado críticamente debe exhibir una necesaria distancia frente a todos los intentos por modificar radical y racionalmente el mundo y la historia, sopesando los resultados poco promisorios de los experimentos revolucionarios del siglo XX. Siguiendo modelos clásicos, como los esbozados por pensadores escépticos y por la medicina clínica, Odo Marquard expuso de modo asistemático su teorema sobre vita brevis, ars longa: la brevedad de la existencia humana hace imposible el probar de manera adecuada todos los modelos y experimentos que proponen una vida mejor en los planos social, político y cultural. No tenemos a libre disponibilidad todo el tiempo requerido para examinar las ventajas y desventajas de todas las propuestas de cambio radical. Puesto que la existencia está determinada en gran parte por lo ya somos y lo que traemos de atrás, lo que realmente podemos modificar no es muy amplio. No podemos disponer del pasado a nuestro antojo, el cual, además, puede ser considerado como una protección contra las inevitables arbitrariedades de todo proyecto reformador. El futuro proviene del pasado y necesita de él. Cuando un buen cirujano opera, elimina sólo lo imprescindible y conserva todo lo posible y conveniente. ${ }^{24}$ Por ello: aquellos que pretenden los cambios tienen que producir y presentar los argumentos realmente convincentes en favor de estos. ${ }^{25}$ Un ejemplo actual: el progreso material y tecnológico no debería ser puesto en duda porque contribuye a superar estructuras anquilosadas y constelaciones injustas -esa es su función primordial e histórica-, sino porque obliga a la humanidad a un tipo único de desarrollo, porque impulsa a un proceso de globalización que puede terminar con el pluralismo cultural y porque quiere eliminar toda forma de contingencia.

La concepción marxista original reproducía igualmente un optimismo exagerado sobre las bondades civilizatorias del colonialismo europeo en el Tercer Mundo, que los mismos marxistas no aceptan en la actualidad. ${ }^{26}$ Aunque suene a exageración, hoy en día puede afirmarse en retrospectiva que la praxis de la Unión Soviética no fue precisamente un ejercicio paradigmático de sentido común (en ninguna de sus acepciones), como tampoco lo fue la doctrina oficial que

New York / Londres: Norton, 1982.

24 Odo Marquard, Abschied vom Prinzipiellen. Philosophische Studien (Adiós a los principios. Estudios filosóficos), Stuttgart: Reclam, 1981, pp. 16-20, 124 sq.

25 Ibid.,p. 77 sq.; cf. el gran estudio sistemático sobre este tema: Harald Weinrich, «Knappe Zeit». Kunst und Ökonomie des befristeten Lebens («Tiempo escaso». Arte y economía de la vida limitada), Munich: Beck, 2004.

26 El testimonio más famoso de este optimismo eurocéntrico es: Karl Marx, Die künftigen Ergebnisse der britischen Herrschaft in Indien (Los resultados futuros del dominio británico en la India), en: Karl Marx / Friedrich Engels, Werke (Obras), Berlin/RDA: Dietz, 1960, t. 9, pp. 220 226. Sobre la temprana crítica de la Escuela de Frankfurt a la concepción mecanicista de progreso material e histórico de Friedrich Engels y del marxismo vulgarizado de los partidos comunistas, cf. el importante texto de Martin Jay, op. cit. (nota 13), p. 156 sq. 
acompañó este proceso evolutivo. No hay duda, por otra parte, de la calidad y profundidad del pensamiento de Antonio Gramsci, quien se ocupó largamente del sentido común en la praxis socio-política, pero este gran ideólogo no aplicó una especie de sentido común a temáticas esenciales de su época, como las estructuras internas de los partidos comunistas, los nexos asimétricos de los mismos con la Unión Soviética, la necesidad de rescatar la democracia representativa pluralista y la mentalidad autoritaria prevaleciente dentro de los partidos de izquierda. ${ }^{27}$ También se podría aseverar que el eurocomunismo fue como una aplicación tardía del sentido común a la práctica de estos partidos en el marco de las exitosas democracias contemporáneas, pero esa práctica estuvo marcada por un oportunismo demasiado transparente y una falta de reflexión teórica a la altura de los tiempos; no llegó a edificar una doctrina duradera del common sense político, y menos una de orientación crítica.

Casi todas las corrientes marxistas no han generado una reflexión aceptable en torno al tema central del sentido común crítico, la preservación de nuestro medio ambiente a largo plazo, tema que engloba (a) las cuestiones ecológicas, (b) la comprensión de los límites que la naturaleza impone a nuestros designios y las limitaciones de la especie humana para comprender contextos muy complejos (y actuar adecuadamente dentro de ellos), y (c) la crítica de las implicaciones del progreso perenne. El tipo actual de progreso amenaza con erradicar toda conexión con nuestro pasado y, por consiguiente, destruir todo factor de identificación con tradiciones que contienen elementos razonables y que nos brindan un sentido de pertenencia a aquello que significa identidad para nosotros. ${ }^{28}$ Esta evolución se basa, según Odo Marquard, en el «monomito» por excelencia: desde la Ilustración del siglo XVIII se ha consolidado el mito del progreso perenne, que nos compele a una única evolución histórica, lo que conlleva la eliminación del plural de las historias particulares y la coerción a volvernos cada vez «más adultos», en sentido socio-político y cultural, es decir a renunciar a toda espontaneidad y a la fantasía creadora de la infancia. ${ }^{29}$ El mundo estaría sometido, según Gerhard Schulze, al juego de la intensificación incesante; el incremento y aumento de todo constituiría el mínimo común denominador de la sociedad. ${ }^{30}$ Como conclusión provisoria podemos decir que el análisis del monomito resultaría un mero ejercicio teórico inofensivo si no se hubieran producido durante el siglo XX las consecuencias

$27 C f$. Nazareno Bravo, «Del sentido común a la filosofía de la praxis. Gramsci y la cultura popular», en Revista de Filosofia (Maracaibo), n ${ }^{\circ}$ 53, mayo-agosto de 2006, pp. 59-75.

$28 C f$. Lord Ralf Dahrendorf, El recomienzo de la historia, Buenos Aires: Katz, 2007.

29 Odo Marquard,op. cit. (nota 24),p.99; Marquard,Apologie des Zufälligen.Philosophische Studien (Apología de lo casual. Estudios filosóficos), Stuttgart: Reclam, 1986, p. 79.

30 Gerhard Schulze, Die beste aller Welten. Wohin bewegt sich die Gesellschaft im 21. Jahrhundert? (El mejor de todos los mundos. Adónde se dirige la sociedad en el siglo XXI?), Frankfurt: Fischer, 2004, p. 18. 
negativas de la concepción del progreso permanente: la destrucción del medio ambiente constituye, como la explosión demográfica, el acondicionamiento de las consciencias y el consumismo masivo, un aspecto de un mismo proceso, que tiende a divinizar los proyectos socio-políticos porque estarían justificados por la razón histórica absoluta. Como afirmó Hans Maier, las «religiones políticas modernas» y el totalitarismo que se deriva de ellas dan origen a un efecto de fascinación, del cual uno puede liberarse sólo mediante enormes esfuerzos del intelecto y de la conciencia moral. ${ }^{31}$ Estas religiones políticas modernas -que a menudo cuentan con una amplia legitimidad democrática-creen que tienen derecho a hacer tabula rasa con el pasado y las tradiciones, ${ }^{32}$ y así imposibilitan la aplicación del sentido común y erosionan el conocimiento de los límites y las limitaciones inherentes a la especie humana.

Desde la Revolución Francesa se pueden detectar nuevos credos pseudoreligiosos, dogmáticos y avasalladores, que prescriben magnas obras de reforma socio-política, reforma que sería obligatoria según las presuntas leyes de la historia. Sería necio, entonces, prestar resistencia a decursos evolutivos de carácter insoslayable y general. El fatalismo de las masas y su aceptación acrítica de esas leyes y esos proyectos se complementan con el voluntarismo soberano de los políticos -que implementan estos proyectos en la praxis sin preocuparse mucho de los costes humanos- y con el oportunismo de los intelectuales, encargados, como es habitual, de justificar esos magnos proyectos mediante argumentos que parezcan irrebatibles. ${ }^{33}$ Admito que estas aseveraciones son incómodas, pero hay que insistir en que la sacralización de la violencia, la maleabilidad de los hombres y la credulidad de las masas han constituido los factores que han hecho posible los diversos totalitarismos del siglo XX.

Ante esta constelación, un sentido común guiado críticamente nos sugiere considerar con más cuidado los impulsos socialpsicológicos del desarrollo histórico y la temática de las mentalidades colectivas, problemática, como se sabe, desatendida por teorías marxistas y afines. En este marco la Escuela de Frankfurt y muy especialmente la obra de Erich Fromm realizaron una labor original y pionera. El motor de la historia no sería en primer lugar la dialéctica de condiciones de producción y relaciones de clase, sino el conflicto del ser humano con la naturaleza y las consecuencias del mismo en la psique individual. Los nexos de

31 Hans Maier, Vorwort (Prólogo), en: Hans Maier (comp.), Wege in die Gewalt. Die modernen politischen Religionen (Caminos a la violencia. Las religiones políticas modernas), Frankfurt: Fischer, 2002, p. 8.

32 Bronislaw Baczko, Hat die Französische Revolution den Totalitarismus hervorgebracht? (Ha generado la Revolución Francesa el totalitarismo?), en: Hans Maier (comp.), op. cit. (nota 31), p. 13 sq.

33 Philippe Burrin, Totalitäre Gewalt als historische Möglichkeit (La violencia totalitaria como posibilidad histórica), en: Hans Maier (comp.), op. cit. (nota 31), p. 185. 
poder se reproducirían en el aparato anímico de cada hombre, ${ }^{34}$ lo que conlleva, manifiestamente, a ver con más detenimiento el rol de los intelectuales, la función de los aparatos ideológicos, el papel de los medios masivos de comunicación y, en general, el peso político de la cultura popular.

En el Tercer Mundo pensadores ilustres y de notable influencia pública han contribuido muy poco al esclarecimiento de esta problemática. La traición de los grandes intelectuales de moda, su frivolidad frente a los asuntos realmente serios y su desconsideración ante los problemas de la vida cotidiana tienen que ver con sus principios morales primarios y su procedencia de una tradición cultural poco crítica y más bien autoritaria y hasta dogmática, disimulada, obviamente, por las modas del día, el relativismo axiológico y la tolerancia superficial con respecto a todo. Esto ha demostrado ser, en el fondo, un fenómeno universal. Los déspotas reales a los que los intelectuales cantan alabanzas -mientras esta actividad brinda réditos público-políticos-corresponden al alma tiránica y egoísta que suelen llevar los intelectuales en su interior. ${ }^{35} \mathrm{Y}$ en nuestra época ello se complementa con una consciencia populista igualitaria, que, como dice George Steiner, está impregnada de envidia, denigración y nivelación hacia abajo, todo ello bajo el rótulo de la moderna democracia de masas. ${ }^{36}$

Por todo ello es imprescindible examinar, aunque sea someramente, el carácter de las mentalidades colectivas y de la función de los intelectuales en el Tercer Mundo. En la mayor parte de este enorme ámbito geográfico las tradiciones y prácticas liberal-democráticas han sido hasta hoy débiles y accidentales. Su consolidación se dificulta por la preponderancia del legado cultural del autoritarismo. Existen, obviamente, muchas excepciones temporales y espaciales a esta afirmación. En dilatadas regiones de Asia, África y América Latina la democracia representativa, liberal y pluralista no ha podido echar raíces profundas, aunque este juicio sea demasiado general y no tenga validez para el futuro. Estas doctrinas fueron importadas en variadas ocasiones y han sido y son desplazadas con la misma facilidad por ideologías nacionalistas y socialistas, que reniegan del legado liberal-individualista y que tienen como objetivo una modernización apresurada dirigida por un Estado centralizado y poderoso. Pensadores nacionalistas y marxistas tienden a otorgar poca importancia a la mentalidad prevaleciente, ya que ésta constituiría el «factor subjetivo» o la «superestructura ideológica», que, en el mejor de los casos, sería barrida del horizonte social por medio de los procesos materiales de urbanización e industrialización. Desde el primer contacto con la cultura europea occidental, los

34 Cf. Martin Jay, op. cit. (nota 13), p. 256.

35 Sobre la predisposición autoritaria de los pensadores postmodernistas más destacados (y sus inspiradores), cf. el instructivo ensayo de Mark Lilla, The Reckless Mind. Intellectuals in Politics, New York: The New York Review of Books, 2001, p. 216.

36 George Steiner, Lecciones de los maestros, México / Madrid: FCE / Siruela, 2004, p. 172. 
intelectuales del Tercer Mundo se destacaron -con pocas y notables excepcionespor adoptar una versión tecnicista e instrumentalista de la modernidad. Esto les permitió tolerar simultáneamente el autoritarismo y el burocratismo rutinarios en la administración pública y mantener los antiguos hábitos sociales, todo esto como una preservación de elementos centrales de la identidad colectiva tradicional. Ellos mismos provenían de una herencia cultural autoritaria, y por ello este fenómeno no les llamó la atención negativamente. Más aun: el autoritarismo -practicado generosamente en regímenes nacionalistas y socialistas- parecía y parece ser altamente favorable para los fines de un progreso acelerado dirigido desde arriba. La mayoría de los intelectuales en Asia, África y América Latina no protestó contra la carencia de valores y procedimientos democráticos en el ámbito socialista (hasta 1989). Tampoco les preocupa la dignidad ontológica inferior atribuida al individuo en sus propios países y el uniformamiento de las pautas de comportamiento que se deriva del actual proceso globalizador. A comienzos del siglo XXI se puede constatar en numerosos países del Tercer Mundo una modernización tecnocrática, que, con muchas limitaciones, ha devaluado el estatismo y el colectivismo, pero ha dejado incólume una porción considerable de la tradición autoritaria y ha generado una amplia homogeneización de toda la vida privada y pública.

Uno de los fundamentos de la mentalidad conservadora-convencional prevaleciente en el Tercer Mundo es paradójicamente una visión acrítica de la modernidad: la convicción de que ésta no es una creación específica de un grupo de naciones -para la que fueron imprescindibles la ciencia y el racionalismo, cosas que se dieron en pocas regiones del mundo-, sino un fenómeno general, casi natural, al cual accederán, más temprano o más tarde, todos los pueblos del mundo. Esta cualidad de universalidad atribuida al proceso de modernización tiende a sobrevalorar sus aspectos positivos (entre otras razones porque serían históricamente obligatorios) y a pasar por alto sus lados negativos. Ya que la modernización es considerada como algo fácticamente inexorable, la consciencia intelectual ha evitado todo cuestionamiento serio y profundo de ese objetivo tan anhelado. En la praxis lo que ha resultado de todo esto puede ser descrito como una modernización imitativa de segunda clase que es vista como si fuese de primera. La consecuencia inevitable es una tecnofilia en el ámbito económico-organizativo: los intelectuales del Tercer Mundo no han desarrollado la ciencia contemporánea ni generado los grandes inventos técnicos, y precisamente por ello tienen una opinión ingenua y casi mágica de todo lo relacionado con la tecnología. Numerosos sectores sociales desdeñan la esfera del pensamiento crítico-científico con el mismo entusiasmo con que utilizan las técnicas importadas, sin reflexionar sobre las consecuencias a largo plazo de tal comportamiento. El resultado general es una mentalidad colectiva predominante en extensas porciones del Tercer Mundo, que puede ser calificada como una fatal combinación de autoritarismo y tecnofilia. Una de mis experiencias recurrentes y deprimentes es la carencia de una consciencia de problemas en el Tercer Mundo 
en torno a los propios asuntos más alarmantes, como la crisis del medio ambiente, las consecuencias de la explosión demográfica, la excesiva burocratización de la administración pública y la necesidad de pensar en el largo plazo.

Esta mentalidad tiene algunos inconvenientes adicionales. No es una actitud que examina con ánimo esclarecedor ni la propia tradición ni la recepción meramente instrumental de la modernidad occidental. Es más bien una renovación de la apología convencional del propio pasado, que ahora, con autoridad «científica», subestima el legado autóctono de despotismo e irracionalidad y sobreestima los aspectos técnico-económicos de la modernidad importada. ${ }^{37}$ Por ello el autoritarismo y la adopción de una modernidad acrítica y tecnocrática van bastante bien de la mano, desatendiendo los problemas del medio ambiente, minimizando las deficiencias de la urbanización acelerada, callando los excesos del desarrollo demográfico y celebrando los modestos logros de una industrialización dudosa. Todo esto representa, por otra parte, un aporte apreciado y popular para consolidar una identidad colectiva devenida precaria, una contribución intelectual muy esperada para reafirmar una nacionalidad que pierde prestigio ante el avance imparable de la modernización occidental. La mencionada mezcla de autoritarismo y tecnofilia es percibida como una reconquista ${ }^{38}$ de la identidad colectiva: la rápida superación de un atraso técnico-industrial considerado como intolerable en el contexto actual de las naciones, una superación que incluye un reforzamiento de tradiciones culturales vistas ahora como amenazadas por la influencia occidental. Esta nueva identidad nacional constituye un puente entre el pasado ahora revalorizado y una aceptación selectiva de la modernidad percibida como algo universal, es decir como algo que supera de lejos el horizonte civilizatorio europeo. El peligro de todo esto reside, evidentemente, en una nueva ilusión colectiva y en la probabilidad de diversas variantes de fundamentalismo. La nueva utopía es concebida como una abundancia de bienes materiales posibilitada por el avance técnico, pero que tiene lugar en una constelación de colectivismo y homogeneidad muy marcada. Por ello el fundamentalismo es considerado como la respuesta premoderna a los desafíos de la modernidad occidental en aquellas regiones del Tercer Mundo que están amenazadas por crisis de identidad y donde predomina una ambigüedad irritante en los valores de orientación: las tradiciones aristocráticas se evaporan, las normativas convencionales de índole autoritaria y colectivista se mantienen y no surgen nuevos valores endógenos de orientación a consecuencia de una debilidad básica frente a la exitosa cultura occidental. ${ }^{39}$

$37 C f$. dos obras que no han perdido vigencia: Samuel Kodjo, Probleme der Akkulturation in Afrika (Problemas de aculturación en Africa), Meisenheim: Hain, 1973; Bassam Tibi, Die Krise des modernen Islams. Eine vorindustrielle Kultur im wissenschaftlich-technischen Zeitalter (La crisis del Islam moderno. Una cultura pre-industrial en la era científico-técnica), Munich: Beck, 1981.

38 Anouar Abdel-Malek, La dialectique sociale, París: Seuil, 1972, p. 69.

39 Cf. Thomas Meyer, Fundamentalismus. Die andere Dialektik der Aufklärung 
El sentido común guiado críticamente se nutre del pensamiento clásico, mitigado por las tareas de la gente consagrada a la vida práctica y a los negocios cotidianos. El common sense anglosajón (tanto en su vertiente británica como en la norteamericana) se originó en aquella atmósfera que gozaba de una cierta autonomía con respecto al poder estatal y que estaba enlazada con el comercio internacional, donde la pluralidad de culturas, perspectivas y visiones del mundo impidió el surgimiento de dogmatismos profundos y permanentes. La tradición empírica, la inclinación a soluciones pragmáticas, la tendencia a sopesar todos los aspectos de un asunto y la propensión a los experimentos fomentaron la consolidación de un common sense que pasó paulatinamente del terreno práctico-pragmático a la esfera del pensamiento y las actividades intelectuales. ${ }^{40}$ Un sentido común guiado críticamente no es un escepticismo doctrinario, y requiere de los esfuerzos sistemáticos desplegados por las escuelas racionalistas de la filosofía y las ciencias sociales y de la permanente reflexión ética. ${ }^{41}$ El pensamiento crítico y radical sólo puede ser fructífero, dijo Erich Fromm, si está unido a la cualidad más valiosa del ser humano: el amor a la vida. ${ }^{42}$

El sentido común guiado críticamente es, en cierta manera, una prolongación del modelo clásico de prudencia y plausibilidad (phronesis), pero enriquecido mediante el análisis desapasionado de la historia universal, decurso, en general, de hechos atroces y simultáneamente banales. No es, por lo tanto, otra versión del «sano sentido común convencional» que, con toda razón, criticara Theodor W. Adorno, actitud que siempre buscó las coincidencias con el poder político del momento y que ha sido responsable por algunas de las aberraciones sociopolíticas más graves de los últimos siglos. ${ }^{43} \mathrm{La}$ concepción clásica de prudencia (autodisciplina, autolimitación) es hoy indispensable porque nos muestra los peligros inherentes a la libertad desbocada y desmesurada, es decir: autodestructiva, que se deriva de la concepción racionalista-absolutista de hacer tabula rasa de la historia y de proponer el cambio por el cambio mismo, como si los seres huma-

(Fundamentalismo.La otra dialéctica de la Ilustración), en:Thomas Meyer (comp.), Fundamentalismus in der Dritten Welt. Die Internationale der Unvernunft (El fundamentalismo en el Tercer Mundo. La Internacional del irracionalismo), Frankfurt: Suhrkamp, 1989, p. 16.

40 Sobre la plausibilidad y necesidad de un common sense en la sociología política y la antropología filosófica, cf. Gerhard Schulze, op. cit. (nota 30), pp. 192-207.

41 Aristoteles, Nikomachische Ethik (Etica a Nicómaco), Munich: dtv 1972, pp. 182-190 (= 1139a - 1141b), la obra de ética más notable escrita jamás.

42 Erich Fromm, Anatomie der menschlichen Destruktivität (Anatomía de la destructividad humana), Reinbek: Rowohlt 1981, p. 490 sq.

43 Theodor W.Adorno, Minima moralia.Reflexionen aus dem beschädigten Leben (Minima moralia. Reflexiones desde la vida deteriorada), Frankfurt: Suhrkamp, 1971,p. 89; Adorno, Aufsätze zur Gesellschaftstheorie und Methodologie (Ensayos sobre teoría de la sociedad y metodología), Frankfurt: Suhrkamp, 1970, p. 115. 
nos estuvieran en la posibilidad de modificar soberanamente el mundo según sus designios momentáneos. ${ }^{44}$

Paradójicamente este tipo de common sense crítico nos hace ver en otra luz -más positiva- algunos aspectos del saber clásico, sobre todo la relación entre metas e instrumentos. Aristóteles trató de manera sistemática el objetivo del Estado, estableciendo que este último, con todas sus instituciones y reglas, no es más que un medio para un fin más alto: la felicidad de sus ciudadanos. El funcionamiento adecuado de una comunidad y la dicha de los mortales pueden ser consideradas como dos caras complementarias del mismo esfuerzo, tales como son, por ejemplo, la contemplación teórica y la praxis política ciudadana. ${ }^{45}$ Este enfoque todavía puede rendir frutos adecuados en el presente: la mejor filosofía de la historia es aquella que examina el desempeño global de un modelo económico-político específico de acuerdo a la felicidad que brinda a sus ciudadanos y al criterio de la vida cotidiana, y no según su cercanía a modelos abstractos de organización social, a utopías literarias o a leyes presuntamente obligatorias del desarrollo histórico. En este contexto es conveniente mencionar que el respeto estricto a los procedimientos democráticos, la corrección en las elecciones, la continuidad de las instituciones del Estado de Derecho y hasta el «patriotismo constitucional» (Habermas) no son probablemente suficientes para configurar un orden razonable; como sostuvo Axel Honneth, hace falta una constelación formada por la solidaridad, el reconocimiento y el amor para asegurar la participación efectiva en la vida pública. ${ }^{46}$

Este ensayo ha tratado de explorar la conveniencia de posiciones intermedias, es decir de evaluar lo positivo de las grandes tendencias históricas, evitando sobreestimar los extremos. Aristóteles entrevió esta posibilidad: las contradicciones convencionales no dejan lugar para terceras posiciones, pero sí los opuestos, que sólo marcan los extremos, entre los cuales son posibles diversas posturas y actitudes. ${ }^{47}$ Para edificar una explicación coherente de problemas actuales se pueden y deben considerar puntos intermedios entre las siguientes posiciones, que de

44 Friedrich Rapp,Destruktive Freiheit.Ein Plädoyer gegen die Masslosigkeit der modernen Welt (La libertad destructiva. Argumentos contra la desmesura del mundo moderno), Münster / Hamburgo: LIT, 2003; cf.la interesante síntesis de Amán Rosales Rodríguez, «¿Libertad sin medida, libertad que destruye? Acerca de un diagnóstico crítico de la modernidad», en Revista de Filosofía de la Universidad de Costa Rica (San José), vol. XLII, no 105, enero-abril de 2004, pp. 175-181.

45 Aristoteles,Politik (Política), Reinbek: Rowohlt 1965,pp. 94 (= 1279 a-b), 97-99 (= 1280 a - 1281 a), 233 sq. (= 1325 b).

46 Axel Honneth, Kampf um Anerkennung. Zur moralischen Grammatik sozialer Konflikte (Lucha por el reconocimiento. Sobre la gramática moral de los conflictos sociales), Frankfurt: Suhrkamp, 1998, p. 65 sq., 68, 73, 278 sq. $C f$. la posición matizada de Jürgen Habermas, Der gespaltene Westen (El Occidente escindido), Frankfurt: Suhrkamp, 2004, p. 64 sqq., 68 sqq.

47 Aristoteles, Metaphysik (Metafísica), Reinbek: Rowohlt 1966, p. 223 (= 1055 b). 
ninguna manera son equidistantes entre ellas y que están mencionadas aquí sólo como ejemplos didácticos de un sentido común guiado críticamente.

Entre la concepción que afirma el sentido pleno de la evolución histórica y el enfoque que proclama el sinsentido primordial de ese desarrollo, parece razonable dudar de un sentido evidente y estable del mismo, pero se puede atribuir un sentido parcialmente satisfactorio a determinados periodos históricos y a ciertos esfuerzos sistemáticos de los seres humanos, destinados a mejorar la convivencia social. La existencia de leyes y etapas obligatorias de la historia es una opción teórica altamente improbable. Pero no todos los sistemas sociopolíticos y económicos se hallan a la misma altura entre sí (o a igual distancia de Dios). Afirmar que todos los modelos culturales son inconmensurables entre sí es un débil consuelo para encubrir las falencias (y la inhumanidad) de numerosos ordenamientos sociales. Existe una gradación cualitativa entre ellos, y los mejores son claramente aquellos que han sabido brindar una vida bien lograda y libertades más amplias a sus habitantes. La existencia de un solo paradigma normativo-positivo de desarrollo es insostenible, pero igualmente la posición que decreta la diversidad e incomparabilidad totales de los regímenes civilizatorios, y así iguala y equipara a todos hacia abajo, hacia el mínimo común denominador, que es a veces la estulticia humana. ${ }^{48}$

El contexto de ideas e instituciones alrededor de la Ilustración europea es algo digno de ser defendido aun hoy y la negación deconstruccionista del racionalismo representa una moda deleznable que no pasará la prueba del tiempo y las generaciones. La apología de las diferencias culturales y sociohistóricas como valores per se, fuera de todo cuestionamiento racionalista, encubre la existencia de prácticas autoritarias que no pueden ser defendidas por ningún argumento racional. El extremo que hay que evitar de todas maneras es la transición de autoritarismo a totalitarismo, posibilidad que ahora, en el Tercer Mundo, se ha acrecentado por el surgimiento de regímenes populistas y fundamentalistas.

Es conveniente adoptar una línea intermedia entre universalismo y particularismo y alcanzar una síntesis fructífera de ambos. Como escribió Mauricio Beuchot, puede darse un tipo de interpretación que sea preponderantemente abierto y plural y, sin embargo, aspire a lograr cierta unidad. ${ }^{49}$ También es adecuada una posición intermedia entre la teoría que califica la política como el juego aleatorio del poder y la concepción de la política como la ocupación más noble para hacer razonable y segura la convivencia humana. Pese a todas sus carencias, la democracia representativa pluralista, originada primeramente en Europa Occidental, sigue siendo el camino menos malo para organizar la

48 George Steiner, op. cit. (nota 36), p. 172.

49 Mauricio Beuchot, Tratado de hermenéutica analógica. Hacia un nuevo modelo de interpretación, México: UNAM / Itaca 2000, p. 11. 
vida social de los mortales, y por ello, junto con el Estado de Derecho, merece ser consolidada y ampliada.

Se trata, en el fondo, de conclusiones de sentido común, dichas además en clave provisoria, que como tales son decepcionantes para el lector que ha buscado respuestas definitivas o novedosas.

H. C. F. Mansilla (nacido en Buenos Aires en 1942; ciudadanías argentina y boliviana de origen) estudió ciencias políticas y filosofía en universidades alemanas. Hizo su Magister rerum politicarum en 1968 y su doctorado en 1973 (ambos magna cum laude). La Universidad Libre de Berlin le confirió la venia legendi en 1976. Ha sido profesor visitante en universidades de Alemania, Australia, España y Suiza. En España fue catedrático visitante del Instituto de Altos Estudios José Ortega y Gasset de la Universidad Complutense. Desde 1999 es regularmente catedrático visitante de la Universidad de Zurich (Suiza). Es miembro de número de la Academia de Ciencias de Bolivia y correspondiente de la Real Academia Española. Por lo demás es escritor independiente. Ha publicado varios libros sobre sociología política, crítica de mentalidades autoritarias y ecología política.

Líneas de investigación:

Sociología política, crítica de las mentalidades políticas.

Correo electrónico: hcf_mansilla@yahoo.com

Website: http://hcf_mansilla.tripod.com 